\title{
Phonological Analysis of Chatkhil Dialect in Noakhali District, Bangladesh
}

\author{
Md. Mostafa Rashel \\ Department of English, Daffodil International University, Bangladesh \\ Email: md.mostafa_rashel@hotmail.com
}

\begin{abstract}
Chatkhil dialect (CD) is one of the different dialects in Noakhali district for its individual phonological, morphological and syntactical features. But in this paper I have tried to analyze Chatkhil dialect on the aspects of phonological features. The consonants of Chatkhil dialect are discussed here according to the place of articulation and manner of articulation. There are some significant rules to determine phonemes and allophones of this dialect. Among them I have used Minimal pair selection test, Contrast test (Initial, Medial and Final contrast) and Sub-minimal pair test. I have got seven oral vowels, five semi-vowels and twenty-two diphthongs of Chatkhil dialect during the research. I also tried to illustrate vowel phonemic contrasts. These entries components are discussed in this paper from the aspects of field linguistics.
\end{abstract}

Index Terms — dialect, phonology, phoneme, manner, semi-vowel, diphthongs

\section{INTRODUCTION}

Dialect is a variety of a language. It is created through the change of a language on the aspects of phonological, morphological and syntactical issue. The first discussion about Noakhali dialect was found in the book of Linguistics Survey of India (1967). The samples of Chagalnaiya (p. 308-11) and Ramganj (p. 312-15) with linguistic features of both dialects were mentioned here. In this book the dialect of Noakhali has been probed including the classification of North-east Bengali's (p. 21-94). Later Ghopal Halder (1929) discussed in details about this dialect under the supervision of Sunitikumar Chatterji (1926). These discussions were more organized. After that, the discussion of Maksudur Rahman Hilali's was published in the journal of Muhammadi in1364 (Maniruzzaman; 1994). In course of time Abul Kalam Manzur Morshed discussed and analyzed the Noakhali dialect in a creative manner in his book of $A$ Study of Standard Bengali and the Noakhali Dialect (1985). Besides, some discussions were published in different papers and journals, but these were not resourceful to be cited in the present research.

Though, some differences are observed among these writers and critics for their different viewpoints. But their evaluation is unique about the origin of Noakhali dialect and they identified that the Noakhali dialect is as the Eastern dialect of Bengali language, i.e., the Mid-Indian Aryan language evolved from the ancient Indo-Aryan language. The preface of this dialect is presented below with the help of a diagram.

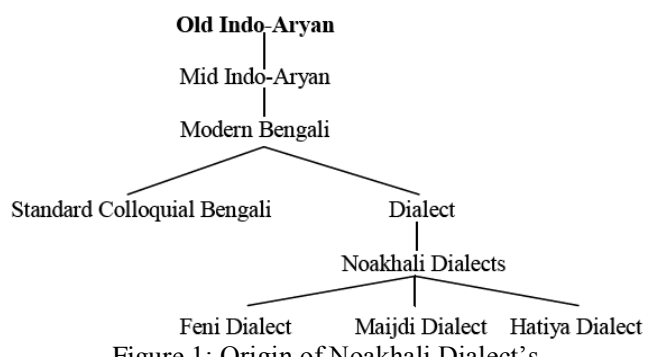

Figure 1: Origin of Noakhali Dialect's

\section{ORIGIN OF CHATKHIL DiALECT}

Chatkhil is one of the smallest upazilla (A division of a District) of Noakhali district according to the area. This subdistrict was established in February 2, 1977. There is no noteworthy reference about the selection of this name. People are saying that there was a bill (a canal) in this area and the inhabitants of this area were irritated by the abundance and disturbance of catpoka (a kind of insect). In course of time, people built up residence around this bill area. As a result bill is transformed as $k^{h} i l$ in dialect form. And from this it has changed into Chatkhil that's mean catpokar bill. (Islam, 1998)

Sub-district Maijdi of Noakhali is called the city and the central point of administrative functions. In course of time, the administrative functions of Maijdi have decentralized and extended toward other upazillas, because of their increasing population, development of civilization and advancement of communication systems. Thus Chatkhil became 
an important area. Nowadays Chatkhil has become the central point of business and administrative activities. The people from neighboring district as well as from other districts are coming to Chatkhil.

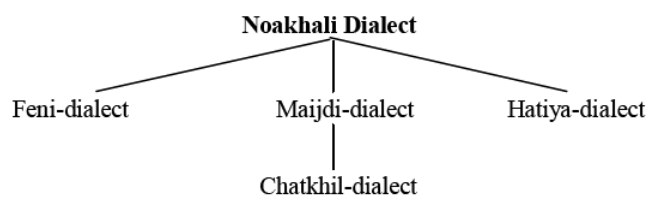

Figure 2: The Origin of Chatkhil Dialect

The distance from Chatkhil to Maijdi is about 100 sq. kilometers (Banglapedia; 2004). The recent development of communication system is unprecedented. The residents of different areas of greater Noakhali immigrated in this area and put up permanent residence from the past. Most of the immigrant people came from Lakshmipur, Laksham, Camilla, Ramganj etc. A lot of people emigrated from far-off greater Chittagong. The total number of people coming from Hatiya is comparatively less due to hindrances. In course of time another dialect i.e., Chatkhil dialect of Noakhali is created for these people of different origin living together.

\section{Phonological Analysis of ChatKhil Dialect}

Though, the Chatkhil dialect is created from the greater Noakhali district dialect; its consonants possess special characteristics. There are twenty-four (24) consonants in this dialect. The consonants of Chatkhil dialect are discussed below according to the place of articulation and manner of articulation.

(a) Place of Articulation

1. Bilabial $: / \mathrm{p} / / \mathrm{p}^{\mathrm{h}} / / \mathrm{b} / / \mathrm{m} /$

2. Dental $\quad: / \mathrm{t} / / \mathrm{t}^{\mathrm{h}} / / \mathrm{d} /$

3. Alveolar $: / \mathrm{n} / / \mathrm{r} / / \mathrm{l} / / \mathrm{f} / / \mathrm{s} /$

4. Palatal $: / \mathrm{c} / \mathrm{f} / / \mathrm{f} /$

5. Palato-alveolar: $/ \mathrm{t} / / \mathrm{t}^{\mathrm{h}} / / \mathrm{d} /$

6. Velar $\quad: / \mathrm{k} / / \mathrm{k}^{\mathrm{h}} / / \mathrm{g} / / \mathrm{y} /$

7. Glottal : /h/

(b) Manner of Articulation

1. Plosive $\quad: / \mathrm{k} / / \mathrm{k}^{\mathrm{h}} / / \mathrm{g} / / \mathrm{c} / / \mathrm{f} / / \mathrm{t} / / \mathrm{t}^{\mathrm{h}} / / \mathrm{d} / / \mathrm{t} / / \mathrm{t}^{\mathrm{h}} / / \mathrm{d} / / \mathrm{p} / / \mathrm{p}^{\mathrm{h}} / / \mathrm{b} /$

2. Nasal $\quad: / \mathrm{n} / / \mathrm{m} / / \mathrm{y} /$

3. Rolling $: / \mathrm{r} /$

4. Retroflex : /r/

5. Fricatives : $/ \mathrm{ç} / / \mathrm{s} / / \mathrm{s} / / \mathrm{f} / / \mathrm{h} /$

6. Lateral : $/ 1 /$

7. Voiceless $: / \mathrm{k} / / \mathrm{k}^{\mathrm{h}} / / \mathrm{c} / / \mathrm{t} / / \mathrm{t}^{\mathrm{h}} / / \mathrm{t} / / \mathrm{t}^{\mathrm{h}} / / \mathrm{p} / / \mathrm{p}^{\mathrm{h}} / / \mathrm{s} / / \mathrm{s} / / \mathrm{h} /$

8. Voiced $\quad: / \mathrm{g} / / \mathrm{f} / / \mathrm{d} / / \mathrm{d} / / \mathrm{b} / / \mathrm{y} / / \mathrm{n} / / \mathrm{m} / / \mathrm{r} / / \mathrm{r} / / \mathrm{l} /$

9. Unaspirated : / $/ / / \mathrm{g} / / \mathrm{c} / / \mathrm{f} / / \mathrm{t} / / \mathrm{d} / / \mathrm{t} / / \mathrm{d} / / \mathrm{p} / / \mathrm{b} / / \mathrm{g} / / \mathrm{n} / / \mathrm{m} / / \mathrm{r} / / \mathrm{r} / / \mathrm{l} / / \mathrm{s} / / \mathrm{s} /$

10. Aspirated $: / \mathrm{k}^{\mathrm{h}} / / \mathrm{t}^{\mathrm{h}} / / \mathrm{t}^{\mathrm{h}} / / \mathrm{p}^{\mathrm{h}} / / \mathrm{h} /$

According to the feature matrix, the consonants of Chatkhil dialect can be mentioned in the following way. 
TABLE 1:

THE CONSONANTS OF CHATKHIL DIALECT ACCORDING TO THE FEATURE MATRIX

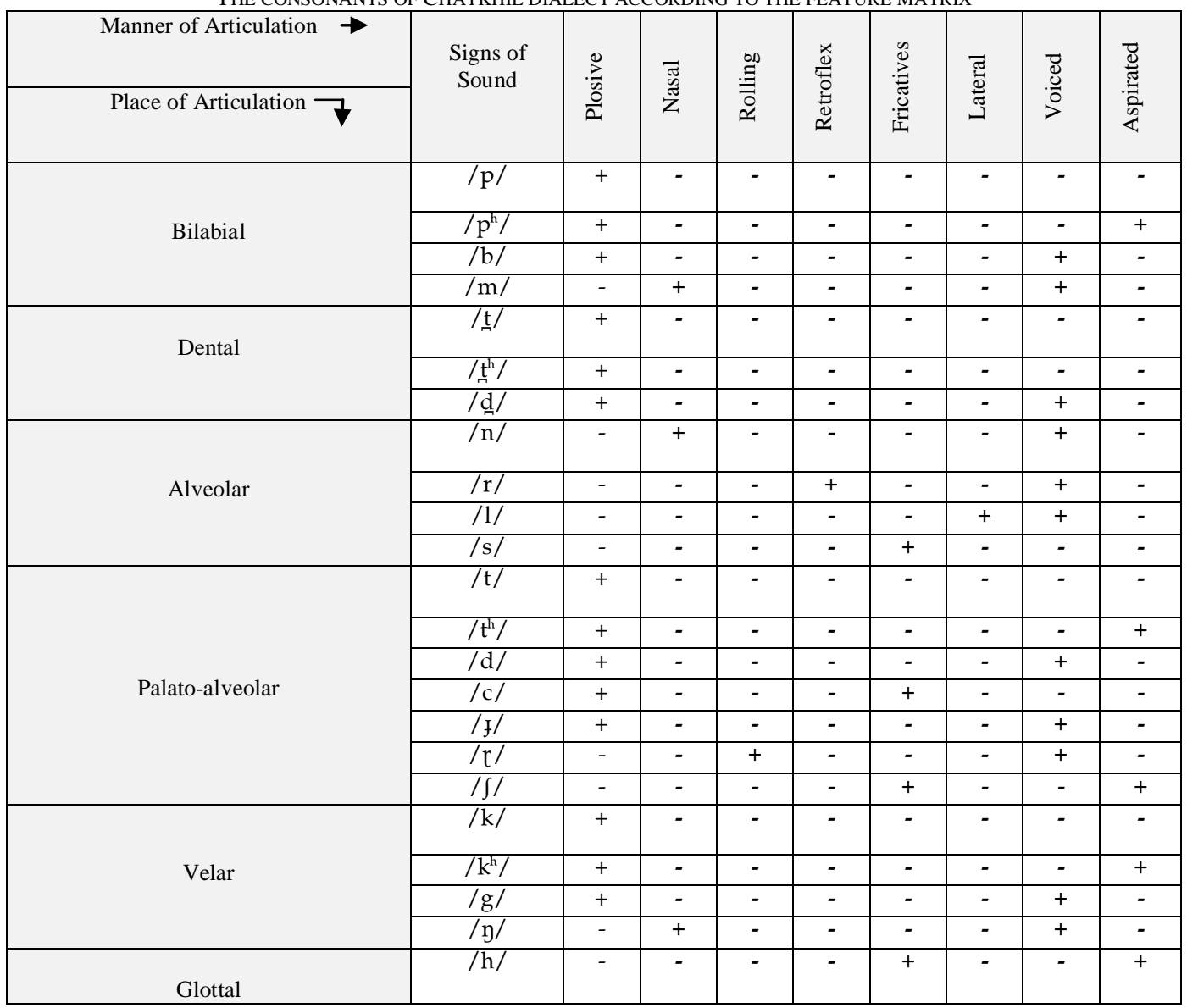

\section{A. Phoneme}

Phoneme is mainly a mental unit of the perception of language of human beings. But this hypothesis has previous stage. It is called phone or sound. It can be called a segment too. There is no obstruction to call phone as a part of speech. It can also be mentioned as the smallest part of suffix form. It is known as a vowels or consonants to the listeners. Speakers always pronounced a sound. But all the time his/her pronouncing sound clusters are not the same. Vowels and consonants are little bit different for the cause of different times or surroundings. Number of phones or fragments of sound exist less or more in every language. As a result it is not easy to discuss them. Thousand of phones of languages are divided into some teams or classes from theoretical aspects. This division or class of phones perception is Phoneme. Phonemes of all languages are well defined and countable (Ali, 2001). There are some significant rules to determine phonemes. These are Minimal pair selections test, Contrast test (i.e. Initial, Medial and Final contrast) and Sub-minimal pair test. The consonant phonemes of Chatkhil dialect can be classified into the following groups with the help of minimal pair test:

\section{Initial Contrast}

i) $/ \mathrm{b} /$

/buk/ 'chest'

ii) $/ \mathrm{k} /$

$/ \mathrm{k}^{\mathrm{h}} \mathrm{al} / \mathrm{c}$ 'canal'

iii) $/ \mathrm{g} /$

/gol/ 'goal'

iv) $/ \mathrm{t} /$

/tora/ 'your'

\section{Medial Contrast}

i) $/ \mathrm{m} /$

/mana/ 'prohibit'

ii) $/ \mathrm{r} /$

/kuri/ 'twenty' /d/

/duk/ 'sorrow/pain'

$/ \mathrm{t} /$

/tal/ 'plum'

/d/

/dol/ 'a tom-tom'

/f/

/fora/ 'pair'

/n/

/nana/ 'grand-father'

/d/

/kudi/ 'to cut' /b/ > /d /

$/ \mathrm{k} />/ \mathrm{t} /$

$/ g />/ d /$

$/ \mathrm{t} />/ \mathrm{f} /$

$/ \mathrm{m} />/ \mathrm{n} /$

$/ \mathrm{r} />/ \mathrm{d} /$ 
iii) $/ \mathrm{p} /$

/mapi/ 'measure'

Final Contrast
i) $/ \mathrm{b} /$
/lab/ 'profit'
ii) $/ \mathrm{y} /$
/hin/ 'horn'
iii) $/ \mathrm{r} /$
/ar/ 'and'
iv) $/ 1 /$
/hol/ 'fruits'

$/ \mathrm{t} /$

/mati/ 'conscious'

$/ \mathrm{p} /$

/lap/ 'jump'

/d/

/hid/ 'back'

$/ \mathrm{n} /$

/an/ 'to bring something's'

$/ \mathrm{r} /$

/hor/ 'light'

$$
/ \mathrm{p} />/ \mathrm{t} /
$$

$$
/ \mathrm{b} />/ \mathrm{p} /
$$$$
/ \mathrm{y} />/ \mathrm{d} /
$$$$
/ \mathrm{r} />/ \mathrm{n} /
$$

$/ \mathrm{l} />/ \mathrm{r} /$

TABLE 2:

INVENTORY OF PHONEMES OF CHATKHIL DIALECT

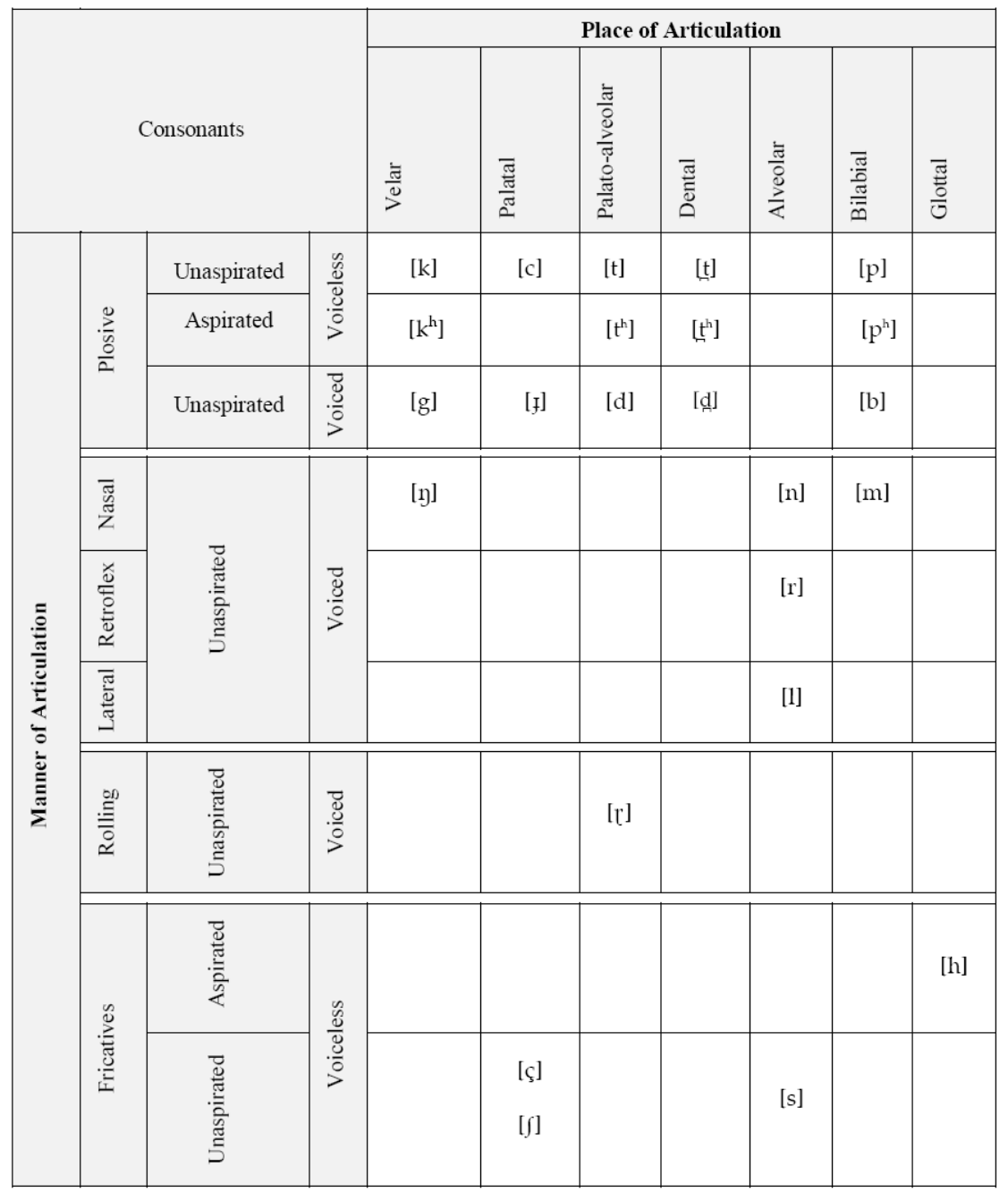

\section{B. Allophones}

It will be easy to explain Allophones if the phoneme is considered to be a family. Family is a cooperative organization and made by the combination of its members. Phonemes alike have numerous members. These members are allophones. The meaning of the words will be changed if the phonemes are changed. But the change in allophones does not resulting in the same. Allophones have significant phonological contextual variants and that can definitely be analyzed. Therefore, the predictable variant of phoneme is called Allophone (Yale, 1995).

The Bengali phonemes have more then one allophones. The Bengali alphabets have a sign of [n]. But it has no pronunciation in standard Bengali language. Everywhere we pronounced it as an alveolar [n]. But if [n] is used as affixed in consonants of classified $t a($ ())-group of standard Bengali, it will be pronounced quietly as like as a retroflex sound. Hence, in Bengali language $[\mathrm{n}]$ is a phoneme and $[\mathrm{n}]$ is its' allophone. Allophones of language are determined 
by rules. To do so, one must be consider as the complimentary distribution and the other is free variation of sound. (Ali, 2001) The allophones of Chatkhil dialect are described below:

1. Standard Bengali language's phoneme /p/ has two allophones [h], [b] in Chatkhil dialect.

/p/ Bilabial, Plosive, Voiceless \& Unaspirated

/h/ Glottal, Voiceless, Aspirated \&Fricatives

/b/ Bilabial, Plosive, Voiced \&Unaspirated

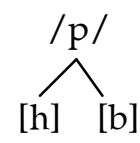

$\mathbf{p}>\mathbf{h}$ : Standard Bengali phoneme /p/ is altered to the allophone [h] and it's used before vowel [a] in the initial position of the word. Examples: [pani] > [hani] (water), [pap] > [hap] (sin)

$\mathbf{p}>\mathbf{b}$ : Standard Bengali phoneme $/ \mathrm{p} /$ is altered to the allophone [b] and it is used after vowel [a] in the final position of the word. Example: [sevenup] > [sevenab] (name of soft drinks)

2. Standard Bengali language's phoneme / $\mathrm{p}^{\mathrm{h}} /$ has two allophones [h], [s] in Chatkhil dialect.

/p/ Bilabial, Plosive, Voiceless \&Aspirated

/h/ Glottal, Voiceless, Aspirated \& Fricatives

/s/Alveolar, Voiceless, Aspirated \& Fricatives

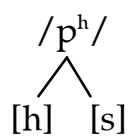

$\mathbf{p}^{\mathbf{h}}>\mathbf{h}$ : Standard Bengali phoneme $/ \mathrm{p}^{\mathrm{h}} /$ is altered to the allophone [h] and it stands before vowel [u] in the initial

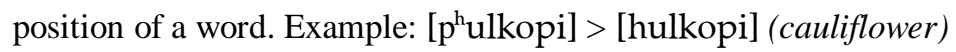

$\mathbf{p}^{\mathrm{h}}>\mathbf{s}$ : Standard Bengali phoneme $/ \mathrm{p}^{\mathrm{h}} /$ is altered to the allophone [s] and it is used before consonant $[\mathrm{t}]$ and after vowel [i] in the medial position of the words. Example: [iptrar] > [istar] (Ifter)

3. Standard Bengali phoneme $/ \mathrm{b}^{\mathrm{h}} /$ has one allophone $[\mathrm{b}]$ in Chatkhil dialect.

$/ \mathrm{b}^{\mathrm{h}} /$ Bilabial, Plosive, Aspirated \& Voiceless

/b/ Bilabial, Plosive, Unaspirated \& Voiced

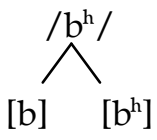

$\mathbf{b}^{\mathrm{h}}>\mathbf{b}$ : Standard Bengali phoneme $/ \mathrm{b}^{\mathrm{h}} /$ is altered to the allophone [b] and it is used after vowel [a] in the final position of a word. Example: [lab $\mathrm{b}^{\mathrm{h}}>$ [lab] (profit). Again phoneme $/ \mathrm{b}^{\mathrm{h}} /$ turn into the allophone [b] and it stands before vowel [a] in the initial position of a word. That's means aspirated becomes unaspirated. Example: $\left[\mathrm{b}^{\mathrm{h}}\right.$ alo] $>[\mathrm{balo}$ ( good/well/fine)

4. Standard Bengali phoneme /c/ has one allophone [ç] in Chatkhil dialect.

/c/ Palatal, Plosive, Unaspirated \& Voiceless

/ç/ Palatal, Plosive, Unaspirated \& Fricatives

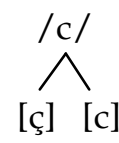

c $>$ ç : Standard Bengali phoneme /c/ is altered to the allophone [ç] and it stands before vowel [u] in the initial position of the words. Example: [cul] > [çul] (hair)

5. Standard Bengali phoneme / $\mathrm{c}^{\mathrm{h}} /$ has two allophones [c], [ç] in Chatkhil dialect.

$/ \mathrm{c}^{\mathrm{h}} /$ Palatal, Plosive, Aspirated \& Voiceless

/c/ Palatal, Plosive, Unaspirated \& Voiceless

/ç/ Palatal, Plosive, Unaspirated \& Fricatives

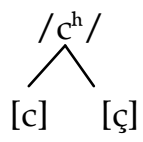

$\mathbf{c}^{\mathrm{h}}>\mathbf{c}$ : Standard Bengali phoneme $/ \mathrm{c}^{\mathrm{h}} /$ is altered to the allophone [c] and it stands before vowel [a] in initial words. Example: [c ${ }^{\mathrm{h}}$ al] $>$ [cal] $($ bark)

$\mathrm{c}^{\mathrm{h}}>\mathrm{c}$ : Standard Bengali phoneme $/ \mathrm{c}^{\mathrm{h}} /$ is altered to the allophone [ç] and it stands before vowel [o] in the initial position of the words. Example: [c $\left.{ }^{\mathrm{h}} \mathrm{obi}\right]>$ [çobi] (picture)

6. Standard Bengali language's phoneme /t/ has one allophone $[d]$ in Chatkhil dialect.

/t/ Palato-alveolar, Plosive, Unaspirated \& Voiceless

/d/ Palato-alveolar, Plosive, Unaspirated \& Voiced

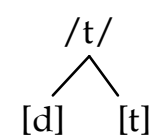

$\mathbf{t}>\mathbf{d}$ : Standard Bengali phoneme / $\mathrm{t} /$ is altered to the allophone [d] and it stands before vowels [a] and [i] in the medial position of a word. Examples: [mota] > [moda] (fat), [ãti] > [adi] (bundle), [ata] > [ada] (coarse flour)

7. Standard Bengali language's phoneme $/ \mathrm{d}^{\text {h }} /$ has one allophone $[\mathrm{d}]$ in Chatkhil dialect.

$/ \mathrm{d}^{\text {h }}$ / Palato-alveolar, Plosive, Aspirated \&Voiced

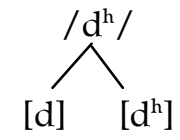




\section{/d/ Palato-alveolar, Plosive, Unaspirated \& Voiced}

$\mathbf{d}^{\mathrm{h}}>\mathbf{d}$ : Standard Bengali phoneme $/ \mathrm{d}^{\mathrm{h}} /$ is altered to the allophone [d] and it stands before [a] vowel in the initial position of a word. Examples: $\left[\mathrm{d}^{\mathrm{h}} \mathrm{al}\right]>[\mathrm{dal}]$ (shield). Again phoneme $/ \mathrm{d}^{\mathrm{h}} /$ is altered to the allophone $[\mathrm{d}]$ and it stands before vowel [e], after vowel [o] in the medial position of the words. Examples: [od $\mathrm{del}]>$ [odel] (plentiful).

8. Standard Bengali language's phoneme $/ \mathrm{t}^{\mathrm{h}} /$ has one allophone $[\mathrm{t}]$ in Chatkhil dialect.

$/ \mathrm{t}^{\mathrm{h}} /$ Dental, Plosive, Aspirated \& Voiceless

/t / Dental, Plosive, Unaspirated \& Voiceless

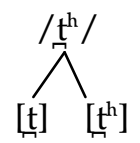

$\mathbf{t}^{\mathrm{h}}>\mathbf{t}:$ Standard Bengali phoneme $/ \mathrm{t}^{\mathrm{h}} /$ is altered to the allophone $[\mathrm{t}]$ and it stands after vowel [a] in a medial position of words. Examples: [matr $\left.t^{\mathrm{h}} \mathrm{a}\right]>$ [mata] (head), [lathi] > [lati] (kick).

9. Standard Bengali language's phoneme / $\mathrm{d}^{\mathrm{h}} /$ has one allophone $[\underset{n}{\mathrm{~d}}]$ in Chatkhil dialect.

$/ \mathrm{d}^{\mathrm{h}} /$ Dental, Plosive, Aspirated \& Voiced

/d/ Dental, Plosive, Unaspirated \& Voiced

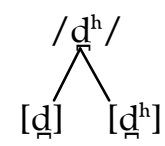

$\mathbf{d}^{\mathrm{h}}>\mathbf{d}$ : Standard Bengali phoneme $/ \mathrm{d}^{\mathrm{h}} /$ is altered to the allophone [d] and it stands before vowel [a] in the initial position of words. Examples: [d $\left.{ }^{\mathrm{h}} \mathrm{an}\right]>$ [dan] (rice), [d d $\left.^{\mathrm{h}} \mathrm{ar}\right]>$ [dar] (to borrow)

10. Standard language's phoneme $/ \mathrm{r} /$ has one allophone $[\mathrm{r}]$ in Chatkhil dialect.

$/ \mathrm{r} /$ Palato-alveolar, Voiced, Unaspirated \& Rolling

/r/ Alveolar, Voiced, Unaspirated \& Retroflex

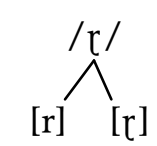

$\mathrm{r}>\mathrm{r}$ : Standard Bengali phoneme $/ \mathrm{r} /$ is altered to the allophone $[\mathrm{r}]$ and it stands before [i] vowel in the medial position of words. Examples: [bari] $>$ [bari] (home), [mari] $>$ [mari] (gum)

11. Standard Bengali language's phoneme $/ \mathrm{r}^{\mathrm{h}} /$ has one allophone $[\mathrm{r}]$ in Chatkhil dialect.

$/ \mathrm{r}^{\mathrm{h}} /$ Palato-alveolar, Voiced, Aspirated \& Rolling

/r/ Alveolar, Voiced, Unaspirated \& Retroflex

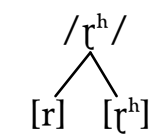

$\mathrm{r}>\mathbf{r}$ : Standard Bengali phoneme $/ \mathrm{r}^{\mathrm{h}} /$ is altered to the allophone $[\mathrm{r}]$ and it stands before [o] vowel in the medial position of words. Example: [gar $\left.{ }^{\mathrm{h}} \mathrm{o}\right]>$ [garo] (Condense)

1. Standard Bengali phoneme $/ \mathrm{h} /$ has one allophone $[\mathrm{a}]$ in Chatkhil dialect

/h/ Glottal, Voiceless, Aspirated \& Fricatives

/a/ Mid, low, central \& open

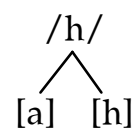

$\mathbf{h}>\mathbf{a}:$ Standard Bengali phoneme $/ \mathrm{h} /$ is altered to the allophone [a] and it stands before consonants [t] and [f] in the initial position of words and one similar vowel will be extinct. Examples: [hat] > [at] (hand), [hafi] > [afi] (laugh).

12. Standard Bengali phoneme / $/ \mathrm{h}$ has one allophone [h] in Chatkhil dialect.

$/ \mathrm{s} /$ Palatal, Voiceless, Unaspirated \& Fricatives

/h/ Glottal, Voiceless, Aspirated \& Fricatives

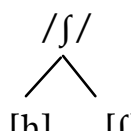

$\int>\mathbf{h}$ : Standard Bengali phoneme $/ \mathrm{J} /$ is altered to the allophone [h] and it stands before vowels [i] and [a] in a medial position of the words. Examples: [jig] $>$ [hip] (horn), [jat] $>$ [hat] (seven).

13. Standard Bengali phoneme /s/ has one allophone [ç] [c] in Chatkhil dialect.

/s/ Alveolar, Voiceless, Unaspirated \& Fricatives

/ç/ Palatal, Plosive, Unaspirated \& Fricatives

/c/ Palatal, Plosive, Unaspirated \& Voiceless

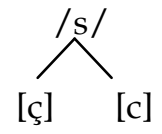

$\int>c ̧$ : Standard Bengali phoneme $/ \int /$ is altered to the allophone [ç] and it stands before [i] vowel in an initial position of the words. Example: [sikka] $>$ [çikka]

$\int>\mathrm{c}$ : Standard Bengali phoneme $/ \mathrm{J} /$ is altered to the allophone [c] and it stands before [o] vowel in an initial

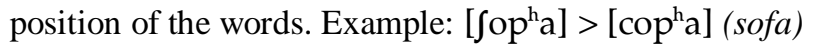

C. Vowel 
We have got seven oral vowels of Chatkhil dialect during the study. These are given beneath.

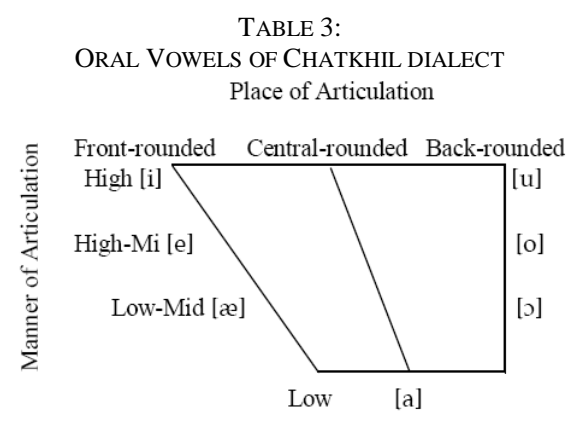

We can substantiate the vowels of Chatkhil dialect according to four units of extent. These are introduced in the following manner according to the dimensions.

\section{Place of Tongue}

We get frontal, central and back vowels according to the position of tongue such as:

Front vowels : [i] [e] [æ]

Central vowels : [a]

Back vowels : [u] [o] [o]

Height of Tongue

According to the height of tongue we get high, high-mid, low-mid and low vowels in this dialect such as:

TABLE 3:

VOWELS OF CHATKHIL DIALECT ACCORDING TO THE HEIGHT AND PLACE OF TONGUE
\begin{tabular}{|c|c|c|c|}
\hline \multirow{2}{*}{ Height of Tongue } & \multicolumn{3}{|c|}{ Place of Tongue } \\
\cline { 2 - 4 } & Front & Central & Back \\
\hline High & $/ \mathrm{i} /$ & & $/ \mathrm{u} /$ \\
\hline High-mid & $/ \mathrm{e} /$ & & $/ \mathrm{o} /$ \\
\hline Low-mid & $/ æ /$ & & $/ \mathrm{J}$ \\
\hline Low & & $/ \mathrm{a} /$ & \\
\hline
\end{tabular}

\section{Lips position}

The position of lips are considered by two dimensions firstly, the rounded or unrounded positions of lips and secondly, the open position of leaps. The following vowels of Chatkhil dialect are given below to consider these two dimensions.

TABLE 4:

VOWELS OF CHATKHIL DIALECT ACCORDING TO THE LIPS POSITIONS

\begin{tabular}{|c|c|c|c|}
\hline & Unrounded & & Rounded \\
\hline Close & $/ \mathrm{i} /$ & & $/ \mathrm{u} /$ \\
\hline Half-close & $/ \mathrm{e} /$ & & $/ \mathrm{o} /$ \\
\hline Half-open & $/ æ /$ & & $/ \mathrm{J} /$ \\
\hline Open & & $/ \mathrm{a} /$ & \\
\hline
\end{tabular}

\section{Position of Soft-palatal}

Nasalization features of vowels are changed according to this position. If we addressed the samples of this dialect

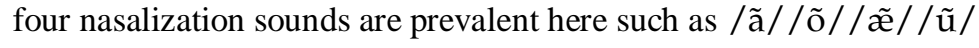

\begin{tabular}{|c|c|c|}
\hline \multirow{3}{*}{ /ã / } & Chatkhil-dialect & Meaning \\
\hline & [ãi] & $\mathrm{I}$ \\
\hline & [hãp] & Snake \\
\hline \multirow[t]{2}{*}{ /õ / } & [hõa] & Cucumber \\
\hline & {$\left[t^{\mathrm{h}} \tilde{o} \mathrm{~d}\right]$} & Lips \\
\hline \multirow[t]{2}{*}{ 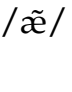 } & [tæ̃a] & Taka \\
\hline & [bæ̃a] & Curve \\
\hline / $\tilde{\mathrm{u}} /$ & [tũii] & You (honored) \\
\hline
\end{tabular}

The nasal consonants are used instead of vowel nasal sounds and it's the especial characteristic of Chatkhil-dialect such as.

$\frac{\text { Standard Bengali }}{\text { [fãd] }} \quad \frac{\text { Chatkhil-dialect }}{\text { [hand] }} \frac{\text { Meaning }}{\text { Traps }}$




$\begin{array}{lll}\text { [cãd] } & \text { [çanni] } & \text { Moon } \\ {\left[\text { bãd }^{\text {a a }}\right.} & \text { [banda] } & \text { Tight } \\ {[\text { kãca] }} & \text { [kaca] } & \text { Green } \\ \text { [ãti] } & \text { [adi] } & \text { Bundle }\end{array}$

D. Semi-vowel

There are five semi-vowels found in this dialect according to Charles Faguson and Munir Chowdery model. These are $/ \mathrm{i} / / \mathrm{e} / / \mathrm{a} / / \mathrm{o} / / \mathrm{u} /$. The use of these vowels is shown below:

Semi-vowel Chatkhil-dialect Standard Bengali Meaning

\begin{tabular}{|c|c|c|c|}
\hline /i/ & [bilai] & [biral] & Cat \\
\hline /en / & [doe] & [d $\left.\mathrm{d}^{\mathrm{h}} \mathrm{Oea}\right]$ & Wash \\
\hline /a / & [bia] & [bibaho] & Marriage \\
\hline /o/ & [jao ] & [jae] & To go \\
\hline$/ \mathrm{u} /$ & [keu] & [keu] & Some one \\
\hline
\end{tabular}

TABLE 5:

THE ORAL VOWEL OF CHATKHIL DIALECT ACCORDING TO THE FEATURE MATRIX

\begin{tabular}{|c|c|c|c|c|c|c|c|}
\hline & /i/ & /e/ & $/ æ /$ & $/ \mathrm{a} /$ & $/ 2 /$ & /o/ & $/ \mathrm{u} /$ \\
\hline High & + & - & - & - & - & - & + \\
\hline High-mid & - & + & - & - & - & + & - \\
\hline Low-mid & - & - & + & - & + & - & - \\
\hline Low & - & - & - & + & - & - & - \\
\hline Front & + & + & + & - & - & - & - \\
\hline Back & - & - & - & - & + & + & + \\
\hline Central & - & - & - & + & - & - & - \\
\hline Rounded & - & - & - & - & + & + & + \\
\hline Unrounded & + & + & + & - & - & - & - \\
\hline Close & + & - & - & - & - & - & + \\
\hline Half-close & - & + & - & - & - & + & - \\
\hline Half-open & - & - & + & - & + & - & - \\
\hline Open & - & - & - & + & - & - & - \\
\hline
\end{tabular}

\section{E. Illustration of Phonemic Contrasts}

\section{Vowel Phoneme}

The contrasts between phonemes are illustrated by minimal or analogues pairs. These contrasts are given below;

Medial contrast
i) /i/
/hid/ 'back'
/e/
$/ \mathrm{i} />/ \mathrm{e} /$
/di/ 'to give'-1st Person
/hed/ 'bally'
ii) $/ \mathrm{s} /$
/de/ 'to give' non-honored
/hol/ 'fruits'
$/ \mathrm{u} /$
$/ \mathrm{o} />/ \mathrm{u} /$
iii) $/ \mathrm{o} /$
/hul/ 'flowers'
/hor/ 'father in law'
/o/
$/ \mathrm{o} />/ \mathrm{J} /$
/dof/ 'crime'
/hor/ 'milk-film'
iv) $/ æ /$
/dos/ 'ten'
/tæl/ 'oil'
$/ \mathrm{u} /$
$/ æ />/ \mathrm{u} /$
Final contrast
i) $/ \mathrm{u} /$
/alu/ 'potato'
/tul/ 'bench'
ii) $/ \mathrm{a} /$
/o/
/alo/ 'Alo- as a name
$/ 0 /$
$/ \mathrm{u} />/ \mathrm{o} /$
$/ a />/ \mathrm{d} /$ 


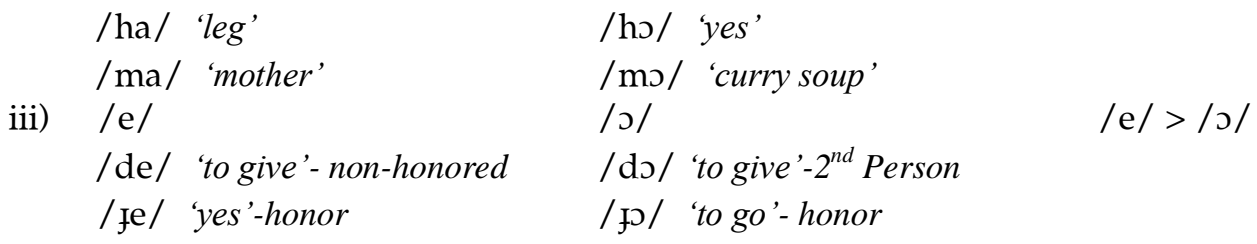

\section{F. Vowel Allophone}

1. Standard Bengali phoneme /a/ has two allophones [i] [o] in Chatkhil dialects.

/a/ mid, low \& close

/i/ front-unrounded, high, close \& unrounded

/ / back, rounded, low-mid \& half-open

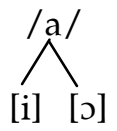

a $>\mathbf{i}$ : Standard Bengali phoneme /a/ is altered to the allophone [i] and used after consonants $[\mathrm{p}]$ and $[\mathrm{n}]$ in the final position of words. Examples: [mapa] $>$ [mapi] (measure), [jana] $>$ [jani] (know)

a $>\mathrm{\jmath}$ : Standard Bengali phoneme $/ \mathrm{a} /$ is altered to the allophone [o] and used after consonants $[\mathrm{n}] \mathrm{and}[\mathrm{h}]$ in the final position of words. Examples: [na] $>$ [no] (negative/no), [hã] $>$ [ho] (positive/yes)

2. Standard Bengali phoneme /e/ has three allophones [a] [æ] [o] in Chatkhil dialects.

/e / high-mid, front-unrounded, rounded \& half-open

/a/ mid-low \& open

$/ æ /$ low-mid, front-unrounded, half-open \& unrounded

/o/ back, rounded, low-mid \& half-open

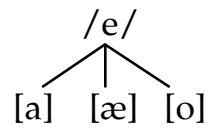

e $>\mathbf{a}$ : Standard Bengali phoneme /e/ is altered to the allophone [a] and used after a consonant [n] in the final position of words. Example: [nei] $>$ [nai] (nothing)

$\mathbf{e}>\mathfrak{x}:$ Standard Bengali phoneme /e/ is altered to the allophone [æ] and used between two consonants in the middle position of words. Example: [lef] > [læj] (tail). Again /e/ is altered to the allophone [æ] and used before consonant $[\mathrm{k}]$ in the initial position of a word. Example: [ek] $>$ [æk] (one)

$\mathbf{e}>\mathbf{o}$ : Standard Bengali phoneme /e/ is altered to the allophone [j] and used between two consonants in the middle position of words. Examples: [gengi] $>$ [gongi] (a vest)

3. Standard Bengali phoneme /i/ has one allophone [e] in Chatkhil dialect.

/e/ high-mid, front-unrounded, unrounded, half-open

/i/ front-unrounded, high, close, unrounded

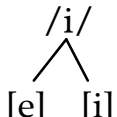

i $>\mathbf{e}$ : Standard Bengali phoneme /i/ is altered to the allophone [e] and used between two consonants in tne middle of a word. Example: [gengi] > [gongi] (a vest). Again /e/ is altered to the allophone [i] and used after a consonant [f] in the final position of a word. Example: [ji] $>$ [je] (yes)

4. Standard Bengali phoneme /o/ has three allophones [a] [o] [u] in Chatkhil dialects.

/o/ back, rounded, low-mid, half-open

/a/ mid, low, open

/o/ back, rounded, low-mid, half-open

/u/ back, high, rounded, open

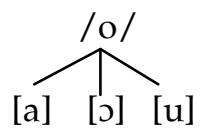

$\mathbf{o}>\mathbf{a}$ : Standard Bengali phoneme /o/ is altered to the allophone [a] and used after a consonant [1] in the final position of a word. Examples: [b $\mathrm{b}^{\mathrm{h}}$ alo] $>$ [bala] (good), [kalo] $>$ [kala] (black)

$\mathbf{o}>0$ : Standard Bengali phoneme /o/ is altered to the allophone $[0]$ and used between two consonants in the middle position of a words. Example: [polau] $>$ [holau] (fried rice)

$\mathbf{o}>\mathbf{u}$ : Standard Bengali phoneme /o/ is altered to the allophone $[\mathrm{u}]$ and used between two consonants in the middle position of a words. Example: [koti] $>$ [kudi] (ten million)

5. Standard Bengali phoneme $/ \mathrm{u} /$ has two allophones [o] [i] in Chatkhil dialects.

$/ \mathrm{u} /$ back, high, rounded, close

/o/ back, rounded, low-mid, half-open

/i/ front-unrounded, high, close, unrounded

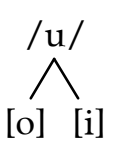


$\mathbf{u}>\mathbf{o}$ : Standard Bengali phoneme $/ \mathrm{u} /$ is altered to the allophone [o] and used between two consonants in the middle positions of a word. Example: [kumra] [komra] (pumpkin)

$\mathbf{u}>\mathbf{i}$ : Standard Bengali phoneme $/ \mathrm{u} /$ is altered to the allophone [i] and used after vowel [a] in the middle position of word. Example: [caul] > [cail] (rice)

6. Standard Bengali phoneme / / has one allophone [i] in Chatkhil dialect.

/ / / back, rounded, low-mid, half-open

/i/ front-unrounded, high, open, unrounded

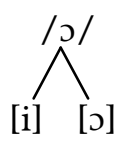

$\boldsymbol{\nu}>\mathbf{i}$ : Standard Bengali phoneme / $/$ is altered to the allophone [i] and used between two consonants in the middle position of a word. Example: [camoc] > [camic] (spoon)

\section{G. Diphthong}

A vowel in which there is a perceptible change of quality during a syllable (Crystal, 1992:156). It is mentionable that each sound is unique and the root of this uniqueness is due to two especial identities of sounds. Firstly, each sound has a place of pronunciation of it's possess. Secondly, each sound has a distinct manner of pronunciation. So diphthong has a glide as like as semi-vowel. Usually the second vowel becomes glide. But there is a distinct difference between glide of diphthong and glide of semi-vowel. The glide of semi-vowel can make a syllable; but the glide of diphthong has not that quality. In brief one can say that, diphthong = vowel + glide (Ali, 2001). In Chatkhil dialect, the diphthong may be oral or nasal, formation of diphthongs are common in Chatkhil dialect due to its phonetic habits, where medial or final consonantal segments are dropped and a vocalic segment is added in compensation (Halder, 1929). The nasal diphthongs are identical in number to their oral counterparts. As nasalization is quite a common phonetic feature of the dialect, nasal diphthongs are widespread in Chatkhil dialect. The total number (22) of oral diphthongs of Chatkhil is described here, as obtained from the speech of informant.

TABLE 6:

DIPHTHONG OF CHATKHIL DIALECT

\begin{tabular}{|c|c|c|c|}
\hline No & Diphthong & Examples & Meaning \\
\hline 1 & [ia] & [hial] & Fox \\
\hline 2 & [iu] & [hiuk] & To learn \\
\hline 3 & [ei] & [beil] & Time \\
\hline 4 & [ea] & [cear] & Chair \\
\hline 5 & [eu] & [deu] & Wave \\
\hline 6 & [ao] & [łao] & Go \\
\hline 7 & [ре] & [kje] & To tell \\
\hline 8 & [oo] & [jon] & Now \\
\hline 9 & [ua] & [çua] & Sour \\
\hline 10 & [oe] & [doe] & To wash \\
\hline 11 & [ui] & [huifa] & coin \\
\hline 12 & [oa] & [noa] & New \\
\hline 13 & [ou] & [bou] & wife \\
\hline 14 & [oi] & [doi] & Yoghurt \\
\hline 15 & [ae] & [ $\left.\mathrm{k}^{\mathrm{h}} \mathrm{ae}\right]$ & To eat \\
\hline 16 & [ij] & [biod] & Danger \\
\hline 17 & [ea] & [dea] & To see \\
\hline 18 & [ue] & [mue] & To mouth \\
\hline 19 & [us] & [huor] & Pig \\
\hline 20 & [ai] & [k $\left.\mathrm{k}^{\mathrm{h}} \mathrm{ai}\right]$ & To eat \\
\hline
\end{tabular}

\section{CONCLUSION}

This is the second attempt to apply the generative transformative model of Chomsky to the phonology of Bengali, more specifically of Standard Bengali and of one other dialect the Chatkhil dialect in Noakhali district, Bangladesh. As it would be expected, some methodological problems arose in finding rules for the language as the work done to date using this model has been largely on non-Indian language. In this research most of the rules are provided by Chomsky- 
Halle (1968). The present research has been essentially contrastive in nature. Bengali has a number of dialects, which vary in great degree in the phonology. The Chatkhil dialect as spoken is a restricted area in Southern Bangladesh, was capered in this study with southern Bengali language in phonology. The contrastive mode of study was helpful in the sense that the degree of variation and similarity of the two forms of Bengali became clan through comparison. In phonology there was a tendency to add some new rules and at the same time to delete some old rules. It was surprisingly found that Chatkhil dialect has more rules for phonetic altercation of consonantal segments. Chatkhil Dialect has some phonological differences with standard Bengali language. These differences are explicit and quantifiable in Chatkhil dialect too. To collect the data of Chatkhil dialect, I have conducted an empirical study in the concerned area. During this study I have twenty-four consonants and seven vowels, which are used in this dialect. Besides, there are four nasalized vowel sounds, five semi-vowels and twenty Diphthongs. One of the most important things is in Chatkhil dialect; the aspiration of sound is abolished here. It means aspirated sounds are pronounced as an unaspirated sound.

\section{REFERENCES}

[1] Ali, Jinnat Imtiaz. (2001). Dhonibijaner Bhumika. Dhaka: Mowla Brothers. 93, 102, 192

[2] National Encyclopedia of Bangladesh. (2004). Banglapedia, 1st Edition. Asiatic Society of Bangladesh.

[3] Chomsky, Noam \& Halle, Moris. (1968). The Sound Pattern of English. Harper and Row: New York.

[4] Crystal, David (1992). The Cambridge Encyclopedia of Language. Cambridge: Cambridge University Press. 156.

[5] Chatterji, Sunitikumar. (1926). The Origin and Development of Bengali Language. Kolkata: Rupa and Co.

[6] Grieson, Georse A. (1967). Linguistic Survey of India. Kolkata. Vol. 1, part 1\& 2 \& Vol. 45, part 1, Motilal Banarsidass: Delhi.

[7] Halder, Ghopal. (1929). A Brief Phonetic Sketch of the Noakhali District of South-Eastern Bengali, Calcutta University Journal of the Department of Letter, Vol. 19, 1-40.

[8] Islam, Fokhrul, Md. (1998). Brihottaro Noakhalir Itihas. Noakhali: Anjuman Ara Begum published. 7, 15, 221.

[9] Maniruzzaman. (1994). Upabhasha Charchar Bhumika. Dhaka: Bangla Academy. 297-98, 300

[10] Morshed, Abul Kalam Manzur. (1985). A Study of Standard Bengali and the Noakhali Dialect. Dhaka: Bangla Academy 36, 302

[11] Yale, Georse. (1995). The Study of Language. Cambridge: Cambridge University Press.

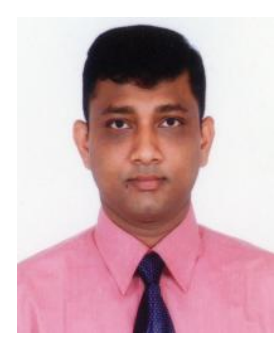

Md. Mostafa Rashel received BA (Hons.) \& MA in Linguistics from University of Dhaka, Bangladesh. His areas of interests are phonetics and Morphosyntax of Bengali, English and Indigenous language.

$\mathrm{He}$ is currently a Senior Lecturer of English (Language and Linguistics) at Daffodil International University and also an M.Phil Researcher in the Department of Linguistics at University of Dhaka, Bangladesh. He has published a number of books and articles in his areas of interest in national and international academic and research journals such as "Morphosyntactic Analysis of Marma Language" (University of Dhaka, Bangladesh, the CDR Journal: A Journal of Center for Development Research), "Morphosyntactic Analysis of Mro Language" (The Dhaka University Journal of Linguistics (DUJL)) and "Introducing Language Technology and Computational Linguistics in Bangladesh" (International Journal of English Linguistics (IJEL), Canada). His current research interests are Endangered Indigenous Languages of Bangladesh, Impact of Single-sex Instruction on Student Motivation and word order typology of English and Bengali. 